\title{
Efeitos do Programa Bolsa Família na Fecundidade das Beneficiárias*
}

\author{
Patrícia Simões $^{\dagger}$, Ricardo Brito Soares ${ }^{\ddagger}$
}

Conteúdo: 1. Introdução; 2. Fecundidade do Ponto de Vista Econômico; 3. Programa Bolsa Família; 4. Metodologia e Base de Dados; 5. Resultados; 6. Conclusão; A. Anexos.

Palavras-chave: Bolsa Familia Program, Fecundity, Count Models.

Códigos JEL: $\quad$ I3, I38.

Procuramos verificar se o Programa Bolsa Família contribui para aumentar a fecundidade entre as beneficiárias, visto que o aumento no tamanho da família, até certo limite, leva ao aumento dos benefícios. Utilizamos um modelo de contagem no qual testamos e tratamos a possibilidade de endogeneidade da variável de política por dois métodos distintos (dois-estágios estilo Heckman e GMM), além de incluir diversos cofatores da PNDS (2006). Os resultados mostram que o PBF não apresentou este efeito, pelo menos no início do programa. Pelo contrário, beneficiárias pareciam mais inclinadas a trocar quantidade por qualidade do que não beneficiárias elegíveis ao programa.

We assessed whether the Bolsa Família Program contributes to increase the fertility among the beneficiaries, since the increase in family size, up to a certain limit, leads to an increase in the benefits. We use a count model in which we test and treat the possibility of endogeneity of the policy variable by two different methods (two-stage method in the spirit of Heckman's models and GMM) and we control for several cofactors obtained from the National DHS (2006). The results show that the PBF didn't have such effect, at least for the beginning of the program. Rather, the beneficiaries seem to be more inclined to trade quantity for quality than non-beneficiaries eligible for the program.

\section{INTRODUÇÃO}

Os programas de transferência condicional de renda (PTCR) têm sido um dos principais instrumentos de combate à pobreza e à desigualdade de renda nos países menos desenvolvidos. Na América Latina,

\footnotetext{
* Os autores agradecem as sugestões metodológicas e bibliográficas dos pareceristas que contribuíram substancialmente para este estudo. Os autores, no entanto, são exclusivamente responsáveis por possíveis falhas despercebidas neste trabalho.

${ }^{\dagger}$ Mestre, Universidade Federal do Ceará (CAEN/UFC). E-mail: pati_simoes@hotmail . com

${ }^{\ddagger}$ PhD, University of New Hampshire. Universidade Federal do Ceará (CAEN/UFC). E-mail: ricardosoares@caen .uf c.br
} 
entre 1997 e 2008, mais de 15 programas foram criados com este intuito comum, mas com variações nas escalas e nos incentivos às condicionalidades sociais (World Bank, 2009). Essas contrapartidas comportamentais dos beneficiários referem-se, em geral, à matrícula ou rendimento escolar para crianças e jovens em idade escolar, e comportamento preventivo e de acompanhamento dos principais serviços de saúde (pré-natal, vacinação, etc.) para os demais membros da família. Já os incentivos podem ser tanto a transferência monetária em isolado, ou sua combinação com serviços sociais/econômicos complementares, como, por exemplo, programas de microcrédito, aperfeiçoamento profissional ou de planejamento familiar.

No Brasil, o Programa Bolsa Família (PBF) atende mais de 12 milhões de famílias em todo o país, tomando as atenções dos pesquisadores principalmente com relação aos seus impactos na pobreza (Marinho et alii, 2011), na distribuição de renda (Soares et alii, 2006) e na imposição das condicionalidades sociais (Soares et alii, 2007, Glewwe e Kassouf, 2008).

No entanto, os PTCR devem ser avaliados não apenas pelos seus impactos nos objetivos principais, mas, também, por possíveis efeitos colaterais (externalidades) gerados pelos mesmos. Teixeira (2008) avaliou o efeito de um choque no orçamento desvinculado dos rendimentos do trabalho e concluiu que o PBF provoca, de forma geral, uma redução significativa da oferta de trabalho quando o valor recebido representa uma parcela importante da renda familiar. Silveira Neto (2008) encontrou evidências de que o PBF reduz os fluxos internos de emigração de regiões mais pobres para as mais ricas no Brasil, embora tal influência pareça não ser efetiva nas migrações de retorno.

Outra possível externalidade em programas de transferência de renda é o aumento da fecundidade entre os mais pobres em regiões de alta densidade populacional, visto que as despesas marginais da criança poderiam ser debitadas do benefício ganho. Como o valor destinado a cada família depende do número de filhos, num cenário de extrema pobreza, quanto maior este recurso, maior seria o estímulo a ter mais um filho para, assim, ter direito a um montante maior do benefício. Por outro lado, a assistência financeira atrelada à imposição de condicionalidades comportamentais poderia desempenhar um efeito contrário se a família decidisse investir mais nos filhos já existentes. O custo de monitoramento dos mesmos pode não ser compensado por transferências extras de baixo valor. Além disso, a assistência social e de saúde do programa é destinada a todos os membros da família subsidiada, oportunizando aos pais instrução e meios de planejamento familiar.

Este efeito ambíguo de aumentos na renda na fecundidade da família foi inicialmente teorizado em Becker (1960) e caracterizado em Schultz (1997) como um efeito substituição entre quantidade e qualidade dos filhos. Empiricamente, alguns trabalhos recentes publicados sobre este tema chegaram a resultados divergentes. Stecklov et alii (2007) avaliaram os efeitos de três PTCR da América Latina (México, ${ }^{1}$ Honduras $^{2}$ e Nicarágua ${ }^{3}$ ) nas taxas de fecundidade das beneficiárias e encontraram efeito positivo e estatisticamente significante apenas para o caso de Honduras. Duchovny (2001) e Baughman e Dickert-Colin (2009) estudaram o Earned Income Tax Credit (EITC) dos Estados Unidos. O primeiro estimou que um benefício adicional às famílias com dois ou mais filhos aumentou a taxa de fecundidade das mulheres brancas, casadas, mães de um único filho, enquanto o segundo concluiu que o incremento resultou em pequenas reduções na fecundidade das mulheres brancas.

No Brasil, poucos estudos empíricos foram realizados. Rocha (2009) e Signorini e Queiroz (2011) utilizaram informações da Pesquisa Nacional por Amostra de Domicílios (PNAD) e estratégias distintas de identificação do efeito do PBF em modelos de probabilidade de ter filhos e chegaram a conclusões semelhantes de ausência de impacto significante.

Este trabalho procura contribuir com a análise do estudo do programa brasileiro (PBF), oferecendo alguns diferenciais específicos. Primeiro, utilizamos a base de dados da Pesquisa Nacional de Demografia

\footnotetext{
${ }^{1}$ Programa de Educação, Saúde e Nutrição (PROGRESA).

${ }^{2}$ Programa de Assistência Familiar (PRAF).

${ }^{3}$ Rede de Proteção Social (RPS).
} 
e Saúde (PNDS), que possui informações mais detalhadas sobre comportamento, características socioeconômicas e cobertura de serviços governamentais das mulheres pesquisadas. Outra particularidade especial desta pesquisa é a possibilidade de identificação do setor censitário do indivíduo, que possui exatamente 12 domicílios circunvizinhos. Esta possibilidade nos permite criar variáveis de vizinhança que serão utilizadas tanto como possíveis efeitos de contágio como instrumentos para a correção da endogeneidade da variável de política. Este efeito endógeno da política pode ocorrer, por exemplo, se as mulheres decidem ter filhos a fim de tornarem-se elegíveis para o programa. Como a amostra é composta apenas por mulheres pobres elegíveis ao PBF, esta possibilidade deve ser considerada nos modelos empíricos.

Segundo, para a análise da fecundidade, utilizamos um modelo de contagem que permite avaliar o efeito da política no número de filhos e não apenas na decisão de ter ou não filhos como ocorre em modelos de decisão binária. Outra vantagem deste modelo é que conseguimos cobrir um tempo maior de exposição das beneficiárias ao programa (30 meses) e, por conseguinte, as suas decisões de fecundidade.

Finalmente, este modelo de contagem é estimado por dois métodos diferentes, considerando-se a endogeneidade do programa (dois estágios estilo Heckman (Terza, 1998) e GMM (Windmeijer e SantosSilva, 1997)). O controle da endogeneidade pode ser fundamental para a identificação do efeito do programa e a utilização de dois métodos de correção permite verificar se o efeito encontrado é robusto às especificações distintas dos modelos empíricos.

Além desta introdução, este trabalho está divido em mais cinco seções. Na seção seguinte, abordamos a fecundidade do ponto de vista da teoria econômica cujas referências clássicas são os trabalhos de Becker (1960) e Becker e Lewis (1973). Na terceira seção descrevemos o PBF e como ele pode vir a influenciar na fecundidade das mulheres beneficiárias. Nas seções seguintes oferecemos os modelos empíricos para esta análise e os resultados de suas estimações. Finalmente, algumas considerações finais inferenciais sobre o programa são reportadas.

\section{FECUNDIDADE DO PONTO DE VISTA ECONÔMICO}

A abordagem econômica da formação das famílias enfatiza o trade-off entre quantidade e qualidade dos filhos (capital humano), e explora como uma mudança na renda e nos preços relativos de cada um destes "bens" influencia a decisão de fecundidade (Becker, 1960).

Em seu modelo teórico, Becker (1960) considera que as crianças são bens normais. No entanto, além da decisão marginal sobre o número de filhos, as famílias também contabilizam melhoras em suas qualidades. Logo, a utilidade dos pais é função de ambos os fatores (quantidade e qualidade), formandose um trade-off cujo resultado depende das elasticidades. Note que estas suposições não implicam que a satisfação ou os custos associados às crianças são moralmente os mesmos que são associados a outros bens duráveis como carros, joias e casas, por exemplo. Porém, a utilidade proveniente delas pode ser comparada através de um conjunto de curvas de indiferença, o qual é determinado pelas preferências dos pais, que, por sua vez, são determinadas pelas características individuais. Para este bem específico - crianças -, tem-se que a elasticidade da qualidade deveria ser, segundo o mesmo artigo, maior do que a elasticidade da quantidade. Ou seja, no caso de um aumento na renda, deveria ser observado um maior investimento nas crianças já existentes em vez da geração de novas crianças. Por simplicidade, assume-se que as famílias têm controle sobre o número de filhos, bem como o espaçamento entre os nascimentos. Dessa forma, além de determinar o número de crianças, a família decide sobre quanto irá gastar com cada uma delas e, neste sentido, um gasto mais alto implica em uma "criança de qualidade mais elevada".

Becker et alii (1990) afirmam que as taxas de retorno em investimentos em capital humano (qualidade) são elevadas em comparação às taxas de retorno em crianças (quantidade) quando o capital humano é abundante. Enquanto que, quando o capital humano é escasso, ocorre o oposto. O resultado 
é que sociedades com capital humano limitado escolhem formar famílias grandes com baixo investimento em cada membro. Os autores mencionam, ainda, a possibilidade de um país alternar deste equilíbrio, dito "Malthusiano", para um equilíbrio de "desenvolvimento", no qual famílias menores têm investimentos maiores, e talvez crescentes, em capital humano e físico, através da criação de políticas que favoreçam este tipo de investimento. Esta mudança, no entanto, seria gradual e acompanharia o próprio processo de transição demográfica dos países.

\subsection{Programas de transferência de renda e fecundidade}

O debate sobre o efeito renda nas decisões de composições familiares pode ser transcrito para o contexto dos programas de transferência de renda. Isto porque, tipicamente, um programa de transferência monetária, que fornece renda de acordo com o número de filhos do titular da família, tende a dar um auxílio maior a famílias mais numerosas, o que pode incentivar o aumento das taxas de fecundidade. Entretanto, um programa de transferência condicional de renda, que exige contrapartidas das famílias assistidas nas áreas de educação e saúde, por exemplo, e que tenha um limite de concessão de benefícios, como é o caso do Programa Bolsa Família e de outros programas implementados na América Latina, pode ter o efeito contrário e estimular a queda destas taxas.

Segundo Becker (1991), o aumento na renda familiar poderia incentivar algum aumento nas taxas de fecundidade se o custo de investimento em capital humano for significativamente alto. Entretanto, Schultz (1997) sugere que as condicionalidades diminuem os custos de investimento na qualidade dos filhos e isto proporciona a diminuição da quantidade de filhos, visto que estes dois bens são substitutos.

Schultz (1973) afirma, ainda, que os efeitos da renda na fecundidade são dificeis de serem identificados por causa da correlação entre a fonte da renda familiar, que seria o salário proveniente do trabalho, e o custo de oportunidade do tempo despendido com as exigências da criança. $O$ fator tempo da mãe, relacionado ao fato dela trabalhar, pode influenciar a decisão da troca da quantidade pela qualidade. Neste caso, a preferência por qualidade passa pela escolha da mãe passar mais tempo com os filhos e menos tempo trabalhando, o que reduz o seu salário proporcionalmente. Esta é uma das razões pelas quais as mães são usualmente as titulares da unidade familiar beneficiada. Os PTCR procuram incentivá-las a dedicarem menos do seu tempo com o trabalho sem que isso resulte na redução dos seus rendimentos, diminuindo, assim, a fecundidade.

Empiricamente e a nível agregado, a relação entre nível de renda per capita e taxa de fecundidade é uma das mais fortes correlações que são observáveis nos possíveis cruzamentos de dados (Galor e Weil, 1993). Mas, quando as análises empíricas são realizadas para analisar efeitos de programas sociais na fecundidade, os resultados variam caso a caso.

O programa federal Earned Income Tax Credit (EITC), nos Estados Unidos, provê redução de imposto de renda ou até mesmo transferência líquida para trabalhadores com baixos salários (renda), sendo esta transferência de crédito dependente e crescente do número de filhos na família. Os efeitos das variações dos benefícios do programa na fecundidade das beneficiárias foram estudados em Duchovny (2001), que encontrou uma elasticidade no número de filhos com relação à renda de $15 \%$ para as mulheres brancas, casadas e com um único filho. Já Baughman e Dickert-Colin (2009) concluíram que um incremento no EITC resulta apenas em reduções extremamente pequenas na fecundidade de mulheres brancas. No Reino Unido, Ohinata (2008) estudou o efeito do Working Families Tax Credit (WFTC) na fertilidade, e observou que mulheres solteiras tiveram a probabilidade de nascimento reduzida e os intervalos entre um filho e outro aumentados. Já as mulheres com parceiros estáveis foram encorajadas a ter o segundo filho mais rapidamente.

Na América Latina, diversos autores estudaram PTCR, sob vários enfoques, e obtiveram resultados distintos. Stecklov et alii (2007) fizeram uso de uma base de dados em painel, ${ }^{4}$ e estimaram modelos de

\footnotetext{
${ }^{4}$ Vale ressaltar que a implementação inicial dos programas foi realizada através de experimentos sociais, com seleção aleatória dos beneficiários.
} 
probabilidade de fecundidade (probit) em primeira diferença e em diferença-da-diferença e verificaram que as beneficiárias do Programa de Assistência Familiar (PRAF), de Honduras, possuíam uma probabilidade maior de engravidar do que as não beneficiárias. Os autores utilizaram a mesma estratégia empírica para estudar o caso do programa Rede de Proteção Social (RPS), da Nicarágua, porém, os resultados não foram conclusivos. Segundo os autores, parte desta diferença de efeitos entre os programas estaria relacionada ao desenho de cada um deles. No PRAF, os ganhos marginais, por filho, no recebimento ou no montante da transferência monetária eram maiores, contrastando com a transferência condicionada lump-sum, independente do número de filhos que é dado nos outros programas. Ainda relacionado ao RPS, Todd et alii (2011) investigaram o efeito deste programa no espaçamento entre os nascimentos ocorridos das beneficiárias e concluíram que o programa aumenta este espaçamento e, com isso, reduz as chances de fecundidade.

O Programa de Educação, Saúde e Nutrição (PROGRESA), do México, também foi avaliado por Stecklov et alii (2007) com resultados semelhantes ao encontrado para o RPS neste estudo, ou seja, sem efeito significante. Este resultado qualitativo também foi encontrado quando o efeito do programa foi medido para o espaçamento entre nascimentos em Feldman et alii (2009). Em contrapartida, Lamadrid-Figueroa et alii (2010) encontraram resultados positivos sobre a influência do programa no uso de contraceptivos por mulheres jovens participantes. Todd e Wolpin (2006) utilizaram um modelo comportamental dinâmico sobre a decisão dos pais em relação ao tamanho da família e investimento na escolaridade das crianças, e identificaram efeitos muito pequenos dos subsídios na fecundidade no longo prazo.

No Brasil, o PBF prevê aumento de transferência conforme o número de filhos na família até certo limite, assim como o PRAF, porém, com benefícios marginais modestos.

\section{PROGRAMA BOLSA FAMÍLIA}

O Programa Bolsa Família é uma política social que tem como um dos objetivos, além de minimizar a pobreza, investir no desenvolvimento do capital humano das crianças pobres através das condicionalidades nas áreas da saúde e da educação. O programa teve seu início em outubro de 2003 com cerca de 3,8 milhões de famílias atendidas, totalizando mais de 15,7 milhões de pessoas. Passados oito anos, o número de famílias beneficiárias alcança a marca de quase 13 milhões, representando, aproximadamente, 50 milhões de pessoas. Atualmente, 13 milhões é, também, o número estimado ${ }^{5}$ de famílias pobres com perfil que se encaixa no PBF.

O programa estabelece duas linhas de pobreza delimitando, através destes valores de corte, o valor do benefício concedido. Os auxílios destinam-se àquelas famílias que vivem em situação de extrema pobreza e de pobreza segundo critérios seletivos estabelecidos conforme a renda familiar per capita, o número e a idade dos filhos.

A Tabela 1 mostra os valores dos benefícios, segundo os diversos critérios para concessão, nos anos de 2004 e 2010. Neste último ano, a configuração do PBF determinava que, para o primeiro grupo, as famílias extremamente pobres, a linha de corte referente à renda familiar mensal era de até $\mathrm{R} \$ 70,00$ per capita. O benefício básico fornecido a essas famílias era de $\mathrm{R} \$ 68,00$ independentemente da composição familiar. Caso houvesse crianças menores de 15 anos e/ou gestante/nutriz, era adicionado um benefício variável correspondente a $\mathrm{R} \$ 22,00$ por pessoa, até o limite de três. E, caso houvesse adolescentes de 16 ou de 17 anos de idade com frequência escolar regular, poderia ser adicionado mais um benefício variável de $\mathrm{R} \$ 33,00$ para cada jovem, até o limite de dois. Somando todos os benefícios a que uma família extremamente pobre tinha direito, obtinha-se o valor máximo de $\mathrm{R} \$ 200,00$ mensais. O segundo grupo compreendia as famílias pobres, cuja renda per capita era definida entre $\mathrm{R} \$ 70,01$ e $\mathrm{R} \$ 140,00$

\footnotetext{
${ }^{5}$ Estimativa feita a partir da combinação da metodologia de Mapas de Pobreza do IBGE, elaborados a partir do Censo Demográfico 2000, da PNAD 2006 e de outros indicadores sócio-econômicos, levando em consideração a renda familiar per capita de até $\mathrm{R} \$ 140,00$ e acrescida de estimativas de volatilidade de renda elaboradas pelo IPEA.
} 
mensais. As regras para a concessão do auxílio para este segmento são as mesmas, porém os benefícios são todos variáveis podendo alcançar, na época, o máximo de $\mathrm{R} \$ 132,00$.

Tabela 1: Programa Bolsa Família: Comparativo entre os anos 2004 e 2010 dos critérios de elegibilidade, tipos e valores dos beneficios

\begin{tabular}{|c|c|c|c|}
\hline \multirow{2}{*}{\multicolumn{2}{|c|}{ Situação familiar }} & \multicolumn{2}{|c|}{ Valor do benefício } \\
\hline & & 2004 & 2010 \\
\hline $\begin{array}{l}\text { POBREZA } \\
\text { EXTREMA }\end{array}$ & $\begin{array}{l}\text { Sem } \\
\text { filhos/gestantes }\end{array}$ & Básico R\$50 & Básico R\$68 \\
\hline $\begin{array}{l}\text { Critério de } \\
\text { definição: }\end{array}$ & $\begin{array}{l}\text { Crianças até } 15 \\
\text { anos e/ou gestante }\end{array}$ & $\begin{array}{l}\text { Básico R\$50 + } \\
\text { Variável R\$15 } \\
\text { (até 3x) }\end{array}$ & $\begin{array}{l}\text { Básico R\$68 } \\
\text { Variável R\$22 } \\
\text { (até } 3 x \text { ) }\end{array}$ \\
\hline $\begin{array}{l}\text { Em 2004: Renda } \\
\text { familiar per capita } \\
\text { até } \mathrm{R} \$ 50\end{array}$ & $\begin{array}{l}\text { Adolescentes de } \\
16 \text { e/ou } 17 \text { anos }\end{array}$ & & $\begin{array}{l}\text { Básico } \mathrm{R} \$ 68+ \\
\text { Variável } \mathrm{R} \$ 33 \\
\text { (até } 2 \mathrm{x} \text { ) }\end{array}$ \\
\hline $\begin{array}{l}\text { Em 2010: Renda } \\
\text { familiar per capita } \\
\text { até } \mathrm{R} \$ 70\end{array}$ & $\begin{array}{l}\text { Crianças e } \\
\text { adolescentes }\end{array}$ & & $\begin{array}{l}\text { Básico } \mathrm{R} \$ 68+ \\
\text { Variável } \mathrm{R} \$ 22 \\
\text { (até } 3 \mathrm{x} \text { ) + } \\
\text { Variável } \mathrm{R} \$ 33 \\
\text { (até } 2 \mathrm{x} \text { ) }\end{array}$ \\
\hline POBREZA & $\begin{array}{l}\text { Sem } \\
\text { filhos/gestantes }\end{array}$ & Não recebe & Não recebe \\
\hline $\begin{array}{l}\text { Critério de } \\
\text { definição: }\end{array}$ & $\begin{array}{l}\text { Crianças até } 15 \\
\text { anos e/ou gestante }\end{array}$ & $\begin{array}{l}\text { Variável R\$15 } \\
\text { (até 3x) }\end{array}$ & $\begin{array}{l}\text { Variável R\$22 } \\
\text { (até } 3 \mathrm{x} \text { ) }\end{array}$ \\
\hline $\begin{array}{l}\text { Em 2004: Renda } \\
\text { familiar per capita } \\
\text { entre } R \$ 50 \text { e } R \$ 100\end{array}$ & $\begin{array}{l}\text { Adolescentes de } \\
16 \text { e/ou } 17 \text { anos }\end{array}$ & & $\begin{array}{l}\text { Variável R\$33 } \\
\text { (até } 2 \mathrm{x} \text { ) }\end{array}$ \\
\hline $\begin{array}{l}\text { Em 2010: Renda } \\
\text { familiar per capita } \\
\text { entre } R \$ 70 \text { e } \mathrm{R} \$ 140\end{array}$ & $\begin{array}{l}\text { Crianças e } \\
\text { adolescentes }\end{array}$ & & $\begin{array}{l}\text { Variável R\$22 } \\
\text { (até 3x)+ } \\
\text { Variável } \mathrm{R} \$ 33 \\
\text { (até } 2 \mathrm{x} \text { ) }\end{array}$ \\
\hline
\end{tabular}

Fonte: Ministério do Desenvolvimento Social e Combate à Fome (MDS), Critérios de Seleção e Valores dos Benefícios (elaboração própria).

Quando uma família ingressa no PBF, tanto ela quanto o governo assumem um compromisso. Em troca do benefício, a família deve se comprometer a realizar algumas contrapartidas comportamentais relacionadas às áreas da saúde, da educação e da assistência social e o governo, por sua vez, se compromete a oferecer condições para as famílias cumprirem com suas condicionalidades. Do ponto de vista do governo, as condicionalidades viabilizam a inserção social através do acesso a direitos básicos contribuindo para a interrupção do ciclo geracional da pobreza. Além disso, é uma maneira de ampliar a oferta e qualificar os serviços públicos essenciais. 
Quanto às exigências relacionadas à saúde, é determinado que crianças com até 7 anos devem manter as vacinações atualizadas e terem seu crescimento acompanhado, gestantes e nutrizes devem realizar consultas pré e pós-natal, mães das crianças que têm até 7 anos devem participar de atividades sociais e educativas relacionadas à saúde e todas estas devem ter acompanhamento nutricional. Referente à educação, a exigência é de $85 \%$ de assiduidade escolar para as crianças e adolescentes até 15 anos. $\mathrm{Na}$ área da assistência social, o programa oferece apoio às crianças em risco ou retiradas do trabalho infantil através de ações sociais e educativas. Aos demais membros das famílias assistidas, recomendase a participação em programas complementares, como cursos profissionalizantes voltados à geração de emprego e renda, cultura, melhoria das condições habitacionais, entre outros. 0 acompanhamento dessas exigências é feita pelos Ministérios da Saúde (MS) e da Educação (MEC) numa ação conjunta que fortalece as ideias de descentralização de responsabilidades e articulação de setores distintos. É importante mencionar que estas condicionalidades tentam estimular, nos pais, a troca da quantidade de filhos pela qualidade dos filhos já existentes, pois as mesmas imputam um custo marginal de dedicação que pode não ser compensado pelo ganho extra do programa.

É exponencialmente crescente o número de artigos no Brasil que avaliam a eficácia do PBF em atingir estas condicionalidades. ${ }^{6}$ Entretanto, há uma carência de produção científica com o objetivo de avaliar o impacto dos PTCR na fecundidade de suas beneficiárias. A busca por trabalhos do gênero resultou em apenas dois exemplares com este tema.

O primeiro, realizado por Rocha (2009), avaliou a influência do PBF nas probabilidades de nascimento no ano precedente através de três metodologias distintas: a) avaliação de um método de tripla diferença (modelo probit); b) efeito da chance de um benefício adicional (modelo probit); c) efeito do tratamento através do método de propensity score matching. Os dados utilizados foram obtidos das PNAD e, os resultados apontaram um efeito negativo, porém não significante, do programa na fecundidade das beneficiárias.

O segundo estudo foi realizado por Signorini e Queiroz (2011) que estimou e comparou efeitos médios de tratamento via propensity score matching para antes e depois da incidência do programa utilizando informações das PNAD de 2004 e de 2006. Os resultados mostraram que, em cada ano, a probabilidade ter filhos era estatisticamente menor para as beneficiárias. No entanto, como a diferença dos efeitos entre períodos não foi significante concluiu-se que o programa não teve impacto.

Este trabalho contribui para a literatura com três variações importantes. A primeira é referente à base de dados, obtida da Pesquisa Nacional de Demografia e Saúde (PNDS) de 2006. Este banco permite o maior controle dos grupos utilizados para as comparações, pois fornece informações diretas sobre o beneficiamento da família pelo programa, além de informações demográficas e comportamentais detalhadas que são cofatores próximos ao evento de maternidade das mulheres pesquisadas. Desta forma, conseguimos controlar de forma mais adequada outros fatores (observados) que influenciam a fecundidade, melhorando a identificação do efeito isolado do programa.

Outra característica especial da PNDS é a possibilidade de se construir modelos com variáveis de vizinhança. Isto porque é possível identificar o setor censitário do indivíduo, o qual possui, além do domicílio de referência, outros 11 domicílios circunvizinhos. As variáveis de vizinhança serão utilizadas para captar tanto possíveis efeitos de contágio como para servir de instrumentos para a correção da endogeneidade da variável de política (Bolsa Família).

O segundo ponto fundamental é a utilização de Modelos para Desfechos de Contagem, bastante utilizados em estudos demográficos (Klawon e Tiefenthaler, 2001, Miranda, 2003, 2008, Monte et alii, 2006). Neste caso, pode-se extrair o efeito do programa no número de filhos e não apenas na probabilidade de tê-los, como ocorre em modelos probabilísticos dicotômicos. Desta forma, evita-se comparar probabilidades iguais com quantidades diferentes. Se, em três anos de exposição ao programa, por exemplo, uma mulher beneficiária teve dois filhos enquanto uma mulher não beneficiária com as mesmas caracterís-

\footnotetext{
${ }^{6}$ Ver Resende e Hermeto (2008), Duarte e Silveira Neto (2008) e Glewwe e Kassouf (2008) para questões relacionadas à educação, e Soares et alii (2007), para efeitos nas condicionalidades relacionadas à saúde.
} 
ticas teve apenas um, ou vice-versa, o efeito do programa, neste caso, não seria capturado em modelos duais de probabilidade. Esta possibilidade de cobertura de um período maior de exposição ao programa é também um diferencial da metodologia deste trabalho. Isto porque as informações contidas na PNAD sobre filhos tidos referem-se apenas ao período de 12 meses anteriores a pesquisa, enquanto o período de exposição analisado neste trabalho é de 30 meses, como veremos na próxima seção.

Finalmente, estimamos o modelo de contagem com teste e correção para um possível problema de endogeneidade da variável indicadora do PBF. Esta possibilidade ocorre se um fator comum, não controlado pelas variáveis explicativas, afeta, simultaneamente, a entrada no programa e a demanda pelo número de filhos. A falta ou mal uso de informações sobre as políticas públicas, por exemplo, assim como barreiras culturais/comportamentais não/ou mal capturadas por outros cofatores observáveis, podem fazer com que uma família que não participa do programa tenha também tendência a ter muitos filhos. Este efeito pode ser mais proeminente no começo do programa quando o grau de cobertura do PBF era reduzido. Adicionalmente, uma família pode interpretar que a participação e/ou recebimento do benefício dependa do número de filhos, o que também torna a variável de política endógena. Neste caso, o controle da endogeneidade é fundamental para a estratégia de identificação do efeito do PBF na fecundidade das beneficiárias.

\section{METODOLOGIA E BASE DE DADOS}

Os possíveis efeitos do Programa Bolsa Família na fecundidade dependem, antes de tudo, do conhecimento funcional do próprio programa por parte das famílias e do seu período de vigência. Portanto, para analisarmos se o programa teve algum efeito no número de nascimento construímos um marco lógico, ilustrado na Figura 1.

O PBF teve início em outubro de 2003, logo, supõe-se que as pessoas que se encaixavam no critério de elegibilidade passaram a sofrer o efeito do programa a partir desta data. Não são considerados na contagem, os filhos nascidos até 9 meses depois do início do programa (julho de 2004), pois as mulheres ainda não eram influenciadas por seu efeito no momento em que tomaram a decisão de engravidar. Desta forma, o período real de exposição e ocorrências dos eventos (nascimentos) neste trabalho é de 30 meses, que correspondem ao intervalo de julho de 2004 até dezembro de 2006. O corte à direita, em 2006, deve-se à restrição do período de realização das entrevistas da Pesquisa Nacional de Demografia e Saúde (2006). Nossa variável dependente de interesse, portanto, é o número de filhos nascidos neste período de exposição aos efeitos do programa.?

Figura 1: Horizonte de tempo: Períodos de contagem das variáveis referentes ao número de filhos

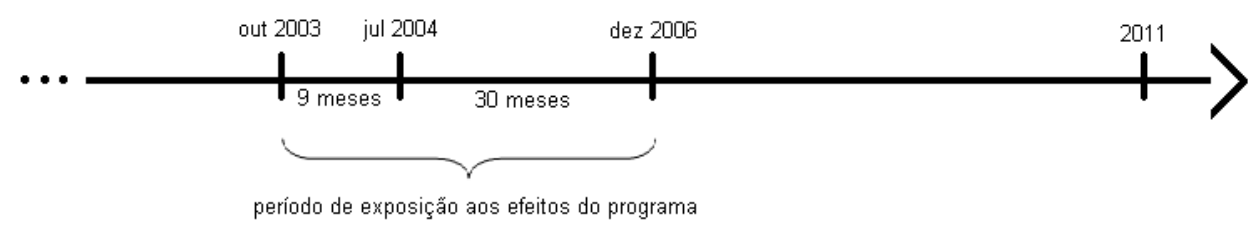

(Elaboração própria).

\footnotetext{
${ }^{7}$ Vale ressaltar que na PNDS é possível distinguir o mês e ano de nascimento dos filhos, o que permite contabilizar o total de filhos neste período específico.
} 
A Tabela 2 descreve esta variável de acordo com a elegibilidade da mulher para o programa, ${ }^{8}$ e do recebimento ou não do benefício do PBF.

Tabela 2: Distribuição dos nascimentos ocorridos nos 30 meses de exposição ao Programa Bolsa Família conforme a condição de elegibilidade das mulheres amostradas

\begin{tabular}{|c|c|c|c|c|c|c|c|}
\hline \multirow{2}{*}{ Mulheres } & \multicolumn{4}{|c|}{ Número de crianças nascidas } & \multirow{2}{*}{$\begin{array}{c}\text { Total } \\
\text { (filhos/mulher) }\end{array}$} & \multirow{2}{*}{$\begin{array}{c}\text { Média } \\
\text { de confiança }{ }^{1}\end{array}$} & \multirow{2}{*}{ Intervalo } \\
\hline & 0 & 1 & 2 & 3 & & & \\
\hline \multirow{2}{*}{ Não-elegível } & 3692 & 666 & 37 & 1 & \multirow{2}{*}{4396} & \multirow{2}{*}{$0,169^{*}$} & $0,157-$ \\
\hline & $84,0 \%$ & $15,2 \%$ & $0,8 \%$ & $0,1 \%$ & & & 0,181 \\
\hline \multirow{2}{*}{ Elegível } & 2409 & 911 & 122 & 3 & \multirow{2}{*}{3445} & \multirow{2}{*}{0,338} & $0,319-$ \\
\hline & $69,9 \%$ & $26,4 \%$ & $3,5 \%$ & $0,1 \%$ & & & 0,356 \\
\hline \multirow{2}{*}{ Não recebe } & 1566 & 616 & 86 & 2 & \multirow{2}{*}{2270} & \multirow{2}{*}{$0,350+$} & $0,326-$ \\
\hline & $69,0 \%$ & $27,1 \%$ & $3,8 \%$ & $0,10 \%$ & & & 0,372 \\
\hline \multirow{2}{*}{ Recebe } & 843 & 295 & 36 & 1 & \multirow{2}{*}{1175} & \multirow{2}{*}{0,315} & $0,284-$ \\
\hline & $71,7 \%$ & $25,1 \%$ & $3,1 \%$ & $0,1 \%$ & & & 0,345 \\
\hline \multirow{2}{*}{ Total } & 6101 & 1577 & 159 & 4 & \multirow{2}{*}{7841} & \multirow{2}{*}{0,243} & $0,233-$ \\
\hline & $77,8 \%$ & $20,1 \%$ & $2,0 \%$ & $0,1 \%$ & & & 0,254 \\
\hline
\end{tabular}

Número de observações: 7841

Fonte: Amostra coletada na Pesquisa Nacional de Demografia e Saúde da Criança e da Mulher (PNDS), 2006, (elaboração própria).

1 Intervalo de Confiança de $95 \%$ para média de filhos/mulher. * Significante a 5\%, + Significante a $10 \%$.

A média incondicional desta variável para a amostra selecionada (7841 mulheres) é de 0,24 filhos por mulher. ${ }^{9}$ As elegíveis para o PBF possuem uma média maior que as não elegíveis, 0,338 versus 0,169 , o que vai ao encontro da teoria de Becker de que o investimento em quantidade é maior nas famílias com pouco capital humano.

Quando se discrimina as elegíveis conforme o recebimento do benefício, percebe-se apenas uma pequena diferença entre as médias de filhos/mulher entre estes dois grupos, 0,04 filhos, significante ao nível de $10 \%$. Esta comparação, no entanto, merece um tratamento condicionado a outros cofatores que influenciam nas decisões das famílias, além de um método de estimação que controle a possível endogeneidade da participação no programa. Este pressuposto é reforçado pelo fato de que, admitindo renda familiar constante ao longo do período analisado, foi observado que $27 \%$ das mulheres elegíveis ao PBF assumiram esta condição via aumento da fecundidade.

\subsection{Estratégia empírica}

Quando o fenômeno a ser estudado é a contagem de eventos, representado por uma variável inteira e não negativa, a utilização de modelos tradicionais lineares normalmente produz estimativas inconsistentes e ineficientes (King, 1988). Para este tipo de variável o modelo de regressão de Poisson é a referência básica. Neste modelo, a variável aleatória de contagem $y_{i}(i=1, \ldots, n)$ segue a seguinte distribuição com média $\mu_{i}$ :

\footnotetext{
${ }^{8} \mathrm{O}$ critério de elegibilidade foi dado pela renda familiar per capita. Ou seja, são elegíveis apenas as mulheres com renda familiar per capita abaixo de $\frac{1}{2}$ salário mínimo vigente na época.

${ }^{9}$ Seleção de mulheres em idade fértil, com menos de 3 filhos antes do início do PBF, e com informações completas. Mais detalhes sobre esta seleção na próxima seção.
} 


$$
P\left(y_{i}\right)=\frac{e^{\mu_{i}} \mu^{y_{i}}}{y_{i} !}
$$

Na especificação do modelo condicional temos $\mu_{i}=\exp \left(x_{i}^{\prime} \beta+\beta_{d} D_{i}\right)$, onde $x$ é um vetor de cofatores, $D$ é uma variável indicadora de tratamento potencialmente endógena, e $\beta$ e $\beta_{d}$ seus respectivos vetores de parâmetros a serem estimados. Na estimação destes parâmetros pelo Método dos Momentos, consideramos o seguinte modelo não linear com erro aditivo de média zero $(\varepsilon)$ :

$$
y_{i}=\exp \left(x_{i}^{\prime} \beta+\beta_{d} D_{i}\right)+\varepsilon_{i}
$$

Na hipótese de exogeneidade das variáveis explicativas temos que $E\left[x_{i} \varepsilon_{i}\right]=E\left[x_{i}\left(y_{i}-\mu_{i}\right)\right]=0$ e o estimador dos $\beta$ pelo Método dos Momentos é o mesmo obtido pela condição de primeira ordem da função de verossimilhança da regressão de Poisson. ${ }^{10}$ Se a variável $D$ for endógena, entretanto, estes estimadores tornam-se inconsistentes e devem ser utilizadas técnicas de estimação capazes de contornar tal problema.

Duas formas tradicionais de correção da endogeneidade em modelos de contagem são: o método de dois estágios desenvolvido em Terza (1998) e o GMM proposto por Windmeijer e Santos-Silva (1997). Estes dois métodos serão utilizados em caso de endogeneidade para verificar se o efeito do programa é robusto às especificações dos modelos.

O método de dois estágios é mais paramétrico e funciona de maneira semelhante ao método de Heckman (Heckman, 1978) para modelos lineares. O modelo estrutural é assumido da seguinte forma:

$$
\begin{array}{r}
y_{i}=\exp \left(x_{i}^{\prime} \beta+\beta_{d} D_{i}\right)+\varepsilon_{i} \\
D_{i}=\left\{\begin{array}{l}
1, \text { se } z_{i} \alpha+v_{i}>0 \\
0, \text { caso contrário }
\end{array}\right. \\
\left(\begin{array}{l}
\varepsilon \\
v
\end{array}\right) \mid x, z \sim \text { Normal }\left[\left(\begin{array}{l}
0 \\
0
\end{array}\right),\left(\begin{array}{ll}
\sigma^{2} & \sigma \rho \\
\sigma \rho & 1
\end{array}\right)\right]
\end{array}
$$

onde $z$ é um vetor de variáveis explicativas exógenas que influenciam na decisão de participação do programa $D,{ }^{11} \alpha$ é um vetor de parâmetros, $v$ é um erro aleatório, e $\rho$ é o parâmetro que captura a correlação entre os erros das equações como estabelecido no sistema. O procedimento tradicional consiste em estimar, no primeiro estágio, um modelo probit para $D$, extrair o fator de correção ${ }^{12}$ e incluí-lo no modelo final de contagem. Staub (2009) sugere estimar o segundo estágio do modelo com um Pseudo-Poisson utilizando o seguinte fator de correção $\Psi$ :

$$
E(y \mid x, d)=\exp \left(x^{\prime} \beta+\beta_{d} D+\theta \Psi\right)
$$

e

$$
\Psi=D \frac{\phi\left(z^{\prime} \alpha\right)}{\Psi\left(z^{\prime} \alpha\right)}+(1-D) \frac{-\psi\left(z^{\prime} \alpha\right)}{1-\Psi\left(z^{\prime} \alpha\right)}
$$

sendo que os $\alpha$ são substituídos por suas estimativas no modelo probit e $\phi$ e $\Phi$ são respectivamente as funções de distribuição e distribuição acumulada normal padrão. A vantagem de utilizar esta estratégia é que ao mesmo tempo em que se produz estimadores de impacto para a variável endógena de política, o modelo gera um teste de endogeneidade para esta mesma variável, dado que $\theta=\sigma \rho$. Assim, se $\theta$ for

$10 \frac{\partial \ln L}{\partial \beta}=\sum x_{i}\left(y_{i}-\mu_{i}\right)=0$.

${ }^{11}$ Podendo incluir $x_{i}$.

${ }^{12}$ A razão inversa de Mills no caso do procedimento de Heckman para os modelos lineares. 
estatisticamente significante sinaliza a presença de endogeneidade. O contraponto desta estratégia é a dependência paramétrica imputada na estruturação do modelo.

Uma forma de correção de endogeneidade menos paramétrica é o Método dos Momentos Generalizados (GMM) proposto por Windmeijer e Santos-Silva (1997). Uma vantagem deste modelo é a produção de estimadores consistentes robustos à atual distribuição da variável de contagem (Schellorn, 2001). Por outro lado, esta técnica é dependente da disponibilidade de um conjunto de variáveis instrumentais $z$, tal que $E[\varepsilon \mid z]=0$. Desta forma podem-se extrair os parâmetros do modelo a partir do seguinte momento: $E[(y-\mu) \mid z]=0$.

Um dos grandes desafios nos modelos empíricos com variáveis instrumentais é encontrar as variáveis que garantam esta propriedade. Neste estudo de caso específico, temos que encontrar uma variável que seja determinante na decisão de busca pelo PBF, mas que não possua influência direta sobre a decisão de composição familiar.

Neste ponto, fazemos uso das informações da PNDS (2006), cujo processo de amostragem aleatória inclui o sorteio de setores censitários e, dentro destes, são escolhidos doze domicílios circunvizinhos. A possibilidade de identificar estes vizinhos na base de dados nos permitiu construir variáveis de vizinhança que podem ser utilizadas como identificadores. Mais especificamente, nossas variáveis instrumentais são o número de vizinhos beneficiados pelo PBF no setor censitário e o número de vizinhos elegíveis ao programa que não são beneficiados. ${ }^{13} \mathrm{O}$ spillover de informações sobre este programa pode ser fator chave na decisão por participar (ou não) do mesmo, sem que esta variável tenha efeito direto na decisão de fecundidade da família da pessoa de referência. Este efeito de spillover, no entanto, pode ser assimétrico entre os elegíveis que recebem ou não o programa na vizinhança, o que nos fez incluir estas duas variáveis como instrumentos no modelo. ${ }^{14}$ Adicionalmente a estas variáveis locais de participação no programa, também incluiremos o identificador na região Nordeste, por ser esta a região que recebeu o maior volume de recursos do programa.

O uso de variáveis geográficas de vizinhança como variáveis instrumentais é comum em modelos de econometria espacial (Case e Katz, 1991), como também em outros modelos estruturais estimados em dois estágios (Rosenzweig e Schultz, 1982). No entanto, em cada estudo de caso é preciso validar a qualidade dos instrumentos com testes estatísticos. 0 teste mais comum utilizado em modelos GMM é 0 teste $J$ de Hansen para sobreidentificação do modelo, cuja hipótese nula é o pressuposto de $E[\varepsilon \mid z]=0$. Vale destacar que o mesmo ainda pode ser utilizado como teste de especificação de modelo (Baum et alii, 2002), e que, juntamente com testes de endogeneidade para modelos de contagem sugeridos em Staub (2009), referendam o uso desta modelagem.

Portanto, o teste e a posterior correção da endogeneidade da variável indicadora dos beneficiários do PBF, juntamente com a possibilidade do uso de vários cofatores demográficos e comportamentais da PNDS (2006), formam nossa estratégia de identificação metodológica do efeito do PBF na fecundidade de suas beneficiárias. Estes cofatores estão dispostos na Tabela 3, anexa, e foram escolhidos com base na literatura e conforme algumas contribuições específicas para este estudo de caso. Destacam-se, entre estes, os relacionados aos fatores de risco à gravidez (Índice de Massa Corporal (IMC) e hábito de fumar), informações de conhecimento e acesso aos serviços de saúde disponíveis (se sabem onde procurar o médico ou se conhecem métodos anticonceptivos, por exemplo), e informações de vizinhança que podem capturar efeitos de interação social na fecundidade (total de vizinhos com menos de cinco anos). ${ }^{15}$

\footnotetext{
${ }^{13}$ Vale ressaltar que neste cálculo do número de vizinhos sempre é excluído a pessoa $i$ que representa a unidade de informação transversal.

${ }^{14}$ Assimetrias desta forma, por exemplo, foram encontradas para modelos de peer effects na decisão de fumar do indivíduo, onde a influência dos fumantes da família era diferente da influência contrária dos não-fumantes (Harris e López-Valcárcel, 2008).

${ }^{15}$ Controlamos as possíveis correlações entre indivíduos do mesmo setor censitário estimando a matriz de variância e covariância com clusters neste nível de agregação.
} 
Complementamos o processo de identificação do efeito do PBF com a seleção amostral das mulheres incluídas nos modelos estimados. Primeiro, incluímos apenas as mulheres com todas as informações para os cofatores. Como estes podem ser determinantes próximos da fecundidade, o controle dos mesmos favorece a inferência da influência direta e líquida da estimativa do parâmetro da variável de política. Segundo, incluímos na amostra apenas mulheres que são elegíveis para o PBF pelo critério de renda per capita familiar abaixo de meio salário mínimo, o que proporciona uma comparação mais adequada entre os grupos de tratamento (mulheres beneficiadas) e controle (mulheres não beneficiadas, mas elegíveis para o programa). Vale destacar que, como foi verificado que existem não elegíveis quanto a este critério que recebem o beneficio, os modelos também foram estimados para uma amostra de mulheres com renda per capita familiar de até 1 salário mínimo. Esta estratégia também foi utilizada em Rocha (2009), que evidenciou este mesmo desarranjo na incidência do programa para os dados da PNAD. Finalmente, a amostra é composta de mulheres entre 16 e 44 anos que tinham menos de três filhos antes do início do programa, dado que apenas estas poderiam receber um adicional do programa por mais uma criança (Tabela 1).

Após este ajuste amostral nota-se, pela Tabela 3, que o perfil mais comum das entrevistadas é de uma jovem na faixa etária de 20 a 24 anos, parda, católica, com até 8 anos de estudo, que experimenta uma união estável, formal ou não, e reside na zona urbana. Metade da amostra é formada por esposas e a composição familiar mais comum é aquela formada por pai, mãe e filhos, seguida por famílias matriarcais. Estes arranjos sugerem que os filhos são criados, predominantemente, pelas mães e vem fundamentar a nomeação da mãe como titular do benefício. Ainda de acordo com a amostra selecionada $34 \%$ da amostra de elegíveis declararam receber transferências do PBF, retratando o período inicial do programa de baixa cobertura, o que favorece uma avaliação comparativa entre elegíveis vis-à-vis uma situação de cobertura próxima à totalidade.

\section{RESULTADOS}

Três modelos foram estimados para duas linhas de faixa de renda familiar (0,5 e 1 salário mínimo), com seus resultados expostos na Tabela 4. No primeiro, foram utilizados todos os cofatores e considerase a variável de política benefício $B F$ como exógena na regressão do modelo. Neste caso não foi possível evidenciar efeitos significantes do Programa Bolsa Família na fecundidade das beneficiárias. Este resultado qualitativo foi o mesmo encontrado em Rocha (2009) e Signorini e Queiroz (2011). No entanto, três testes de endogeneidade sugeridos por Staub (2009), e mostrados na Tabela 5, mostram a necessidade de controle para este problema.

Quando a endogeneidade da política é considerada, seja no modelo de dois estágios ou no modelo GMM, a mesma passa a ser negativa e estatisticamente significante indicando que as beneficiárias tiveram taxas de fecundidade menores que as não beneficiárias no período analisado de exposição ao programa. Embora os modelos tenham pressupostos diferentes ambos mostraram-se válidos, pois atestamos a significância do fator de correção $\psi$ no modelo de dois estágios (Tabela 4) e verificamos via teste $J$ de Hansen a validade dos instrumentos utilizados no modelo GMM (Tabela 5). ${ }^{16}$

Além disso, o resultado qualitativo encontrado é robusto não apenas para a especificação do modelo, mas também para a faixa de renda limite de inclusão na amostra. Neste aspecto, é interessante observar que, nas especificações dos modelos, o efeito pontual do PBF diminui quando aumentamos o limite de 0,5 para 1 salário mínimo, o que é esperado dado que a taxa de fecundidade é menor em faixas de rendas mais altas, que possuem uma menor representatividade de beneficiárias.

\footnotetext{
${ }^{16}$ Vale destacar que o teste $J$ de Hansen foi realizado, também, para todas as combinações dois a dois dos três instrumentos utilizados (vizinhos beneficiados, vizinhos elegíveis não beneficiados e dummy para a região Nordeste), sendo a hipótese nula de validade dos instrumentos não rejeitada ao nível de $5 \%$ em todos os testes. Também se constatou a significância estatística isolada ou em combinações dos instrumentos nos modelos probit de probabilidade de recebimento do BF, o que confirma a qualidade dos mesmos.
} 
A evidência de efeito negativo do PBF na fecundidade é favorável à leitura de que os condicionantes do programa estão estimulando a troca de quantidade por qualidade entre as suas beneficiárias. Pode-se conjecturar que, para estas mulheres, os custos marginais de cumprimento dos condicionantes podem ser maiores do que o benefício extra recebido pelo filho adicional que, na época de implantação do programa, era de apenas $\mathrm{R} \$ 15,00$ mensais. Ou seja, o custo de monitoramento é maior que a transferência adicional.

É possível, também, que o diferencial de fecundidade verificado entre beneficiárias e não beneficiárias estivesse sendo induzido por estas últimas em forma de auto-seleção. As não beneficiárias poderiam pensar que ter mais filhos implicaria em maiores possibilidades de recebimento inicial das transferências. Embora esta auto-seleção possa estar contribuindo para o efeito endógeno encontrado neste trabalho, poder-se-ia esperar, neste caso, um aumento na taxa de fecundidade média, o que não ocorreu no período analisado.

Stecklov et alii (2007) sugere que os efeitos dos PTCR na fecundidade podem ocorrer ou via absorção de comportamentos induzidos pelas condicionalidades ou por outras externalidades. A obrigatoriedade de participação em oficinas de planejamento familiar, por exemplo, poderia induzir o conhecimento e uso de métodos contraceptivos que influenciariam na redução comparativa da fecundidade. Por outro lado, se o programa induz um aumento no número de casamentos e/ou parcerias informais, por exemplo, é provável que haja um incremento da fecundidade.

Estes mecanismos de transmissões, em parte, foram atestados nas análises dos cofatores dos modelos estimados. Encontrou-se que o conhecimento de informações sobre planejamento familiar de fato induz uma diminuição no número de filhos, enquanto que as mulheres em regime de união com parceiros possuem, naturalmente, mais filhos. O curioso, neste último caso, foi o efeito maior para mulheres em união informal em comparação com aquelas casadas formalmente.

$\mathrm{O}$ fator renda mostrou-se altamente significativo para a redução na expectativa de filhos, mesmo entre os mais pobres. Se considerarmos que as transferências do PBF também estão incluídas na renda total domiciliar, podemos acreditar que o programa, via transferências, também possa reforçar este efeito negativo.

Entre os efeitos de outros cofatores, destaca-se como contribuição desta pesquisa a análise do efeito de vizinhança nas questões demográficas. Observa-se que o número de crianças no entorno do domicílio da beneficiária influencia positivamente na demanda por mais filhos, evidenciando uma possível externalidade cultural local.

Por outro lado, raça e religião são aspectos que parecem não afetar a decisão sobre a fecundidade em nenhuma dos modelos estimados, o que releva limites nos efeitos sócio-culturais. Quanto à idade, todas as faixas etárias apresentaram efeitos significativos e coeficientes negativos, indicando que o auge da fecundidade ocorreu na faixa etária de 20 a 24 anos, considerada como base.

Portanto, a combinação do efeito do PBF com os efeitos dos diversos cofatores parece mostrar uma melhora qualitativa na composição familiar entre os mais pobres. É importante ressaltar, no entanto, que a troca da quantidade por qualidade ainda é um processo em andamento no Brasil e fatores como a oferta de serviços e características da vizinhança podem influenciar neste processo e deveriam, portanto, serem consideradas na formulação e no acompanhamento das políticas públicas.

\section{CONCLUSÃO}

O Brasil vem experimentando reduções nas taxas de fecundidade desde a década de 60 . O número médio de filhos por mulher passou de 6,3 para 2,3 neste espaço de cinco décadas, inclusive no segmento de baixa renda (Alves, 2009). Neste sentido, surgem dúvidas quanto ao papel do Programa Bolsa Família neste processo de transição demográfica, visto que experiências em outros países mostraram que programas de transferência de renda podem aumentar a taxa de fecundidade (Stecklov et alii, 2007). 
O presente trabalho propôs-se avaliar os efeitos do PBF nas taxas de fecundidade das beneficiárias, sendo a identificação deste efeito realizada por um modelo demográfico de contagem que testa e trata o problema de endogeneidade da variável de política por dois métodos tradicionais: dois estágios estilo Heckman (Terza, 1998) e GMM (Windmeijer e Santos-Silva, 1997). Utilizando-se uma base de dados (PNDS, 2006) que possibilita o controle de diversos cofatores comportamentais e a contabilização dos nascimentos ocorridos durante os 30 meses iniciais de exposição ao programa de mulheres beneficiárias e não beneficiárias, os resultados dos modelos estimados mostraram que o efeito deste programa foi negativo e significante. Ou seja, as beneficiárias tiveram taxas de fecundidade esperadas significativamente menores que as elegíveis não beneficiárias, principalmente no segmento de renda mais baixa. O diferencial deste resultado em relação aos outros estimados para o caso brasileiro (Rocha, 2009, Signorini e Queiroz, 2011) está na significância estatística encontrada. Uma possível explicação para este diferencial seria metodológica, dado que o modelo de contagem utilizado neste trabalho cobre um tempo maior de exposição ao programa, o que permite capturar o efeito que o programa pode ter no espaçamento entre filhos. Isto ocorreu, por exemplo, na análise do programa Rede de Proteção Social da Nicarágua, onde o mesmo não mostrou influencia significante na probabilidade de ter filhos (Stecklov et alii, 2007), mas sim, no intervalo de tempo entre eles (Todd et alii, 2011).

$O$ efeito negativo encontrado neste trabalho sinaliza que os condicionantes para a manutenção do benefício do PBF impõem, de fato, um "custo" de cuidado aos filhos já nascidos que não é compensado por transferências extras para filhos adicionais. $O$ fato de não haver aumento na demanda por filhos sugere que o valor do auxílio concedido não é suficientemente atrativo para o aumento da fecundidade. Logo, fornecer recursos para os demais membros das famílias com mais de 3 filhos não impactaria, ceteris paribus, na composição destas famílias beneficiárias.

É importante salientar, no entanto, que os resultados deste estudo foram obtidos para o início da vigência do programa, quando sua taxa de cobertura e o seu conhecimento ainda eram insipientes. Desta forma, inferências semelhantes para os anos mais recentes demandam estudos complementares.

Ademais, o equilíbrio no planejamento familiar passa pela disposição da mulher em fazê-lo espontaneamente. Fontes (2008) explica que existe uma diferença considerável entre o conhecimento e a prática. Ou seja, aumentar o nível de informação não significa, necessariamente, modificar o comportamento endógeno, pois este deve ser inerente à imposição de condicionalidades. Neste contexto, outra questão relevante advinda dos resultados é se o efeito do PBF deriva, de fato, de uma maior conscientização das mulheres mais pobres beneficiárias, ou se elas estão apenas respondendo às exigências das condicionalidades do programa. Neste aspecto, bases longitudinais que incluem informações para ex-beneficiárias contribuiriam para esta questão.

\section{BIBLIOGRAFIA}

Alves, J. E. D. (2009). Redução da pobreza e da fecundidade. Disponível em: http://www.ie.ufrj . $\mathrm{br} /$ aparte/pdfs/reducao_da_pobreza_e_da_fecundidade_09ago09.pdf. Acesso em 14 jun 2010.

Baughman, R. \& Dickert-Colin, S. (2009). The earned income tax credit and the fertility. Journal of Population Economics, 22:537-563.

Baum, C. F., Shaffer, M. E., \& Stillman, S. (2002). Instrumental variables and GMM: Estimation and testing. Working Paper 545, Boston College Economics.

Becker, G. S. (1960). An economic analysis of fertility. In Coale, A., editor, Demographic and Economic Change in Developed Countries, pages 209-231. Princeton University Press, Princeton, NJ.

Becker, G. S. (1991). A Treatise on the Family. Harvard University Press, Cambridge. 
Becker, G. S. \& Lewis, H. G. (1973). On the interaction between the quantity and quality of children. Journal of Political Economy, 82:S279-S288.

Becker, G. S., Murphy, K. M., \& Tamura, R. (1990). Human capital, fertility and economic growth. Journal of Politic Economy, 98:S12-S37.

BRASIL (2011). Ministério do Desenvolvimento Social e Combate à Fome. Programa Bolsa Família. Disponível em http://www.mds.gov.br/bolsafamilia. Acesso em 03 ago 2011.

Case, A. \& Katz, L. (1991). The company you keep: The effects of the family and neighborhood on disadvantaged youths. Working Paper 3705, NBER.

Duarte, G. B. \& Silveira Neto, R. M. (2008). Avaliando o impacto do programa bolsa família sobre a frequência escolar: $\mathrm{O}$ caso da agricultura familiar no nordeste do Brasil. In Anais ANPEC. Disponível em http://www . anpec.org.br/encontro2008/artigos/200806301113020- .pdf. Acesso em 02 ago. 2012.

Duchovny, N. J. (2001). The Earned Income Tax Credit and Fertility. Tese de Doutorado, University of Maryland.

Feldman, B. s., Zaslavsky, A. M., Ezzati, M., Peterson, K. E., \& Mitchell, M. (2009). Contraceptive use, birth spacing, and autonomy: An analysis of the oportunidades program in rural Mexico. Studies in Family Planning, 40:51-62.

Fontes, M. (2008). Marketing Social: Novos Paradigmas. Elsevier, Brasília.

Galor, O. \& Weil, D. N. (1993). The gender gap, fertility and growth. Working Paper 4550, NBER.

Glewwe, P. \& Kassouf, A. L. (2008). O impacto do programa bolsa família no total de matrículas do ensino fundamental, taxas de abandono e aprovação. Prêmios de Gestão e Estudo do MDS. Disponível em: http://www .ipc-undp.org/publications/mds/11P.pdf . Acesso em: 02 dez. 2011.

Harris, J. E. \& López-Valcárcel, B. G. (2008). Asymmetric peer effects in the analysis of cigarette smoking among young people in the United States, 1992-1999. Journal of Health Economics, 27:249-264.

Heckman, J. (1978). Dummy endogenous variables in a simultaneous equation system. Econometrica, 46:931-959.

King, G. (1988). Statistical models for political science event counts: Bias in conventional procedures and evidence for the exponential Poisson regression model. American Journal of Political Science, 32:838863.

Klawon, E. \& Tiefenthaler, J. (2001). Bargaining over family size: The determinants of fertility in Brazil. Population Research and Policy Review, 20:423-440.

Lamadrid-Figueroa, H., Ángelesa, G., Mroz, T., Urquieta-Salomón, J., Hernández-Prado, B., Cruz-Valdez, A., \& Téllez-Rojo, M. M. (2010). Heterogeneous impact of the social programme Oportunidades on use of contraceptive methods by young adult women living in rural areas. Journal of Development Effectiveness, 2:74-86.

Marinho, E., Linhares, F., \& Campelo, G. (2011). Os programas de transferência de renda do governo impactam a pobreza no Brasil? Technical report, CAEN/UFC.

Miranda, A. (2003). Socio-economic characteristics, completed fertility, and the transition from low to high order parities in México. Technical report, Economics Department, University of Warwick. 
Miranda, A. (2008). Planned fertility and family background: A quantile regression for count analysis. Journal of Population Economics, 21:67-81.

Monte, S., Magalhães, M., \& Lazo, A. (2006). Modelo Log-Poisson para a análise da fecundidade marital. In XV Encontro Nacional de Estudos Populacionais, ABEP, Caxambú, MG.

Ohinata, A. (2008). Fertility response to financial incentives evidence from the working families tax credit in the UK. Working paper, University of Warwick, Department of Economics, Coventry.

Resende, A. C. C. \& Hermeto, A. M. (2008). Avaliando resultados de um programa de transferência de renda: O impacto do bolsa-escola sobre os gastos das famílias brasileiras. Estudos Econômicos, 38.

Rocha, R. (2009). Programas condicionais de transferência de renda e fecundidade: Evidências do bolsa família. In Brazilian Meeting of Econometrics, North America. Disponível em: http://virtualbib. fgv.br/ocs/index.php/sbe/EBE09/paper/view/1104. Acesso em: 28 set. 2010.

Rosenzweig, M. R. \& Schultz, T. P. (1982). The behavior of mothers as inputs to child health: The determinants of birth weight, gestation, and rate of fetal growth. In Fuchs, V. R., editor, Economic Aspects of Health. University of Chicago Press, Chicago.

Schellorn, M. A. (2001). A comparison of alternative methods to model endogeneity in count models. An application to the demand for health care and health insurance choice. Research Paper 40, SEDAP.

Schultz, T. P. (1973). A preliminary survey of economic analyses of fertility. American Economic Review, 63:71-78.

Schultz, T. P. (1997). The demand for children in low income countries. In Rosenzweig, M. R. \& Starck, O., editors, Handbook of Population and Family Economics. Elsevier, Amsterdam.

Signorini, B. A. \& Queiroz, B. L. (2011). The impact of bolsa família program in the beneficiary fertility. Texto para Discussão 439, Cedeplar.

Silveira Neto, R. M. (2008). Do public income transfer to the poorest affect internal inter-regional migration? Evidence of the case of Brazilian bolsa família program. In Anais ANPEC. Disponível em http://www . anpec.org.br/encontro2008/artigos/200807111106330- .pdf. Acesso em 02 ago. 2012.

Soares, F. V., Ribas, R. P., \& Osórios, R. G. (2007). Evaluating the impact of Brazil's bolsa família: Cash transfer programmes in comparative perspective. Evaluation Note 1, International Poverty Center, PNUD.

Soares, F. V., Soares, S., Medeiros, M., \& Osórios, R. G. (2006). Programas de transferência de renda no brasil: Impactos sobre a desigualdade. Technical report, Centro Internacional da Pobreza IPEA/PNUD e DISOC/IPEA.

Staub, K. E. (2009). Simple tests for exogeneity of a binary variable in count data regression models. Communications in Statistics - Simulation and Computation, 38:1834-1855.

Stecklov, G., Winters, P., Todd, J., \& Regalia, F. (2007). Unintended effects of poverty programmes on childbearing in less developed countries: Experimental evidence from Latin America. Population Studies: A Journal of Demography, 61:125-140.

Teixeira, C. G. (2008). Análise do impacto do programa bolsa família na oferta de trabalho de homens e mulheres. Prêmios de Gestão e Estudo do MDS. Disponível em: http://www.ipc-undp.org/ publications/mds/27P.pdf. Acesso em: 02 dez. 2011. 
Terza, J. V. (1998). Estimating count data models with endogenous switching: Sample selection and endogenous treatment effects. Journal of Econometrics, 84:129-154.

Todd, J. E., Winters, P., \& Stecklov, G. (2011). Evaluating the impact of conditional cash transfer programs on fertility: The case of the Red de Protección Social in Nicaragua. Journal of Population Economics, 25:267-290.

Todd, J. E. \& Wolpin, K. I. (2006). Assessing the impact of a school subsidy program in Mexico: Using a social experiment to validate a dynamic behavioral model of child schooling and fertility. American Economic Review, 96:1384-1417.

Windmeijer, F. \& Santos-Silva, J. (1997). Endogeneity in count data models: An application to demand for health care. Journal of Applied Econometrics, 12:281-294.

World Bank (2009). Conditional cash transfers: Reducing present and future poverty. A World Bank Policy Research Report. Washigton, DC. Disponível em: http: //siteresources . worldbank .org/ INTCCT/Resources/5757608-1234228266004/PRR-CCT_web_noembargo.pdf. Acesso em: 10 mar. 2011. 


\section{A. ANEXOS}

Tabela A-1: Descrição e médias das variáveis utilizadas

\begin{tabular}{|c|c|c|}
\hline Variáveis & Descrição & Média \\
\hline \multicolumn{3}{|l|}{ Variável de política } \\
\hline \multirow{2}{*}{ Benefício Bolsa Família } & 1 se participa do Programa Bolsa Família & 0,339 \\
\hline & 0 se não participa do Programa Bolsa Família & \\
\hline \multicolumn{3}{|c|}{ Características Individuais e de Comportamento } \\
\hline \multirow[t]{2}{*}{ idade19 } & 1 se idade entre 15 e 19 anos & 0,221 \\
\hline & 0 se outra faixa etária & \\
\hline \multirow[t]{2}{*}{ idade24 } & 1 se idade entre 20 e 24 anos & 0,245 \\
\hline & 0 se outra faixa etária & \\
\hline \multirow[t]{2}{*}{ idade29 } & 1 se idade entre 25 e 29 anos & 0,205 \\
\hline & 0 se outra faixa etária & \\
\hline \multirow[t]{2}{*}{ idade34 } & 1 se idade entre 30 e 34 anos & 0,146 \\
\hline & 0 se outra faixa etária & \\
\hline \multirow[t]{2}{*}{ idade39 } & 1 se idade entre 35 e 39 anos & 0,113 \\
\hline & 0 se outra faixa etária & \\
\hline \multirow[t]{2}{*}{ idade44 } & 1 se idade entre 40 e 44 anos & 0,069 \\
\hline & 0 se outra faixa etária & \\
\hline \multirow[t]{2}{*}{ cor_branca } & 1 se raça branca & 0,298 \\
\hline & 0 se outra raça & \\
\hline \multirow[t]{2}{*}{ cor_parda } & 1 se raça parda & 0,541 \\
\hline & 0 se outra raça & \\
\hline \multirow[t]{2}{*}{ cor_negra } & 1 se raça negra & 0,108 \\
\hline & 0 se outra raça & \\
\hline \multirow[t]{2}{*}{ cor_outra } & 1 se raça amarela ou indígena & 0,053 \\
\hline & 0 se outra raça & \\
\hline \multirow[t]{2}{*}{ religião_sem } & 1 se não possui religião & 0,082 \\
\hline & 0 se possui religião & \\
\hline \multirow[t]{2}{*}{ religião_católica } & 1 se religião católica & 0,686 \\
\hline & 0 se possui outra religião & \\
\hline \multirow[t]{2}{*}{ religião_evangélica } & 1 se religião evangélica & 0,206 \\
\hline & 0 se possui outra religião & \\
\hline \multirow[t]{2}{*}{ religião_outra } & 1 se religião espírita ou afro-brasileira & 0,026 \\
\hline & 0 se possui outra religião & \\
\hline
\end{tabular}


Tabela 3 - Descrição e médias das variáveis utilizadas (cont.)

\begin{tabular}{|c|c|c|}
\hline Variáveis & Descrição & Média \\
\hline \multicolumn{3}{|l|}{ Variável de política } \\
\hline \multirow{2}{*}{ Benefício Bolsa Família } & 1 se participa do Programa Bolsa Família & 0,339 \\
\hline & 0 se não participa do Programa Bolsa Família & \\
\hline \multicolumn{3}{|l|}{ Características Familiares } \\
\hline \multirow[t]{2}{*}{ união_sem } & 1 se não está em união estável & 0,382 \\
\hline & 0 se está em união estável & \\
\hline \multirow[t]{2}{*}{ união_formal } & 1 se está em união formal & 0,277 \\
\hline & 0 se não está em união formal & \\
\hline \multirow[t]{2}{*}{ união_informal } & 1 se está em união informal & 0,341 \\
\hline & 0 se não está em união informal & \\
\hline \multirow[t]{2}{*}{ arranjo_casal com filhos } & 1 se família composta por casal com filhos & 0,745 \\
\hline & 0 se outro tipo de arranjo familiar & \\
\hline \multirow[t]{2}{*}{ arranjo_casal sem filhos } & 1 se família composta por casal sem filhos & 0,046 \\
\hline & 0 se outro tipo de arranjo familiar & \\
\hline \multirow[t]{2}{*}{ arranjo_monoparental pai } & 1 se família composta por pai e filhos & 0,016 \\
\hline & 0 se outro tipo de arranjo familiar & \\
\hline \multirow[t]{2}{*}{ arranjo_monoparental mãe } & 1 se família composta por mãe e filhos & 0,170 \\
\hline & 0 se outro tipo de arranjo familiar & \\
\hline \multirow[t]{2}{*}{ arranjo_outro } & 1 se outro arranjo familiar & 0,023 \\
\hline & 0 se algum arranjo familiar citado & \\
\hline \multirow[t]{2}{*}{ parentesco_chefe } & 1 se responsável financeira pelo domicílio & 0,062 \\
\hline & 0 se tem grau de parentesco com o responsável financeiro & \\
\hline \multirow[t]{2}{*}{ parentesco_cônjuge } & 1 se cônjuge do responsável financeiro pelo domicílio & 0,520 \\
\hline & 0 se outro parentesco & \\
\hline \multirow[t]{2}{*}{ parentesco_filha } & 1 se filha/enteada do responsável financeiro pelo domicílio & 0,327 \\
\hline & 0 se outro parentesco & \\
\hline \multirow[t]{2}{*}{ parentesco_outro } & $\begin{array}{l}1 \text { se outro grau de parentesco com o responsável financeiro } \\
\text { pelo domicílio }\end{array}$ & 0,091 \\
\hline & 0 se responsável, cônjuge ou filha/enteada & \\
\hline densidade domiciliar & $\begin{array}{l}\text { densidade domiciliar - razão entre o número de componentes } \\
\text { da família e o número de quartos de dormir }\end{array}$ & 2,201 \\
\hline renda_smpc & $\begin{array}{l}\text { valor da renda média por componente familiar, em salários } \\
\text { mínimos }\end{array}$ & 0,643 \\
\hline
\end{tabular}


Tabela 3 - Descrição e médias das variáveis utilizadas (cont.)

\begin{tabular}{|c|c|c|}
\hline Variáveis & Descrição & Média \\
\hline \multicolumn{3}{|l|}{ Variável de política } \\
\hline \multirow{2}{*}{ Benefício Bolsa Família } & 1 se participa do Programa Bolsa Família & 0,339 \\
\hline & 0 se não participa do Programa Bolsa Família & \\
\hline \multicolumn{3}{|c|}{ Capital Humano e Conhecimentos Relacionados } \\
\hline \multirow[t]{2}{*}{ educação0 } & 1 se analfabeto & 0,019 \\
\hline & 0 se alfabetizado & \\
\hline \multirow[t]{2}{*}{ educação4 } & 1 se tem de 1 a 4 anos de estudo & 0,200 \\
\hline & 0 se outro nível de escolaridade & \\
\hline \multirow[t]{2}{*}{ educação8 } & 1 se tem de 5 a 8 anos de estudo & 0,393 \\
\hline & 0 se outro nível de escolaridade & \\
\hline \multirow[t]{2}{*}{ educação11 } & 1 se tem de 9 a 11 anos de estudo & 0,370 \\
\hline & 0 se outro nível de escolaridade & \\
\hline \multirow[t]{2}{*}{ educação12m } & 1 se tem 12 ou mais anos de estudo & 0,019 \\
\hline & 0 se outro nível de escolaridade & \\
\hline \multirow[t]{2}{*}{ método contraceptivo } & 1 se conhece algum método contraceptivo & 0,976 \\
\hline & 0 se não conhece nenhum método contraceptivo & \\
\hline \multirow[t]{2}{*}{ planejamento familiar } & $\begin{array}{l}1 \text { se ouviu falar sobre planejamento familiar nos últimos me- } \\
\text { ses (rádio, televisão, jornal, cartazes, panfletos, novela, pales- } \\
\text { tra, comunidade, internet) }\end{array}$ & 0,850 \\
\hline & $\begin{array}{l}0 \text { se não ouviu falar sobre planejamento familiar nos últimos } \\
\text { meses }\end{array}$ & \\
\hline \multicolumn{3}{|l|}{ Oferta de Serviços } \\
\hline \multirow[t]{2}{*}{ residência urbana } & 1 se domicílio urbano & 0,63 \\
\hline & 0 se domicílio rural & \\
\hline cuidado médico_ & 1 se sabe onde procurar cuidado médico & 0,642 \\
\hline onde procurar & 0 se não sabe onde procurar cuidado médico & \\
\hline cuidado médico_ & 1 se considera o local onde pode obter cuidado médico longe & 0,387 \\
\hline considera longe & $\begin{array}{l}0 \text { se não considera o local onde pode obter cuidado médico } \\
\text { longe }\end{array}$ & \\
\hline cuidado médico_ & $\begin{array}{l}1 \text { se tem medo de não ser atendida ao procurar cuidado mé- } \\
\text { dico }\end{array}$ & 0,636 \\
\hline medo de não ser atendida & $\begin{array}{l}0 \text { se não tem medo de não ser atendida ao procurar cuidado } \\
\text { médico }\end{array}$ & \\
\hline \multicolumn{3}{|l|}{ Fatores de Risco } \\
\hline filhos maiores de 2,5 anos & $\begin{array}{l}\text { número de filhos nascidos antes da implantação do Programa } \\
\text { Bolsa Família }\end{array}$ & 0,901 \\
\hline imc & $\begin{array}{l}\text { índice de massa corporal - razão entre peso e quadrado da } \\
\text { altura }\end{array}$ & 24,037 \\
\hline \multirow[t]{2}{*}{ fumante } & 1 se tem o hábito de fumar & 0,129 \\
\hline & 0 se não tem o hábito de fumar & \\
\hline
\end{tabular}


Tabela 3 - Descrição e médias das variáveis utilizadas (cont.)

\begin{tabular}{|c|c|c|}
\hline Variáveis & Descrição & Média \\
\hline \multicolumn{3}{|l|}{ Variável de política } \\
\hline \multirow[t]{2}{*}{ Benefício Bolsa Família } & 1 se participa do Programa Bolsa Família & 0,339 \\
\hline & 0 se não participa do Programa Bolsa Família & \\
\hline \multicolumn{3}{|l|}{ Vizinhança } \\
\hline total de vizinhos & $\begin{array}{l}\text { número total de crianças menores de } 5 \text { anos no conglome- } \\
\text { rado, excluindo residentes no domicílio de referência }\end{array}$ & 7,198 \\
\hline \multicolumn{3}{|l|}{ crianças } \\
\hline percentual de vizinhos & $\begin{array}{l}\text { percentual de mulheres no conglomerado, excluindo a entre- } \\
\text { vistada de referência }\end{array}$ & 0,346 \\
\hline mulheres & & \\
\hline
\end{tabular}

Fonte: Amostra coletada na Pesquisa Nacional de Demografia e Saúde da Criança e da Mulher (PNDS) 2006, (elaboração própria). 
Tabela A-2: Modelos estimados

\begin{tabular}{|c|c|c|c|c|c|c|}
\hline \multirow{2}{*}{$\begin{array}{l}\text { Variável dependente } \\
\text { Número de nascimentos no } \\
\text { período de exposição ao PBF }\end{array}$} & \multicolumn{2}{|c|}{$\begin{array}{l}\text { Modelo } \\
\text { exógeno }\end{array}$} & \multicolumn{2}{|c|}{$\begin{array}{c}\text { Modelo } \\
\text { dois estágios }\end{array}$} & \multicolumn{2}{|c|}{$\begin{array}{l}\text { Modelo } \\
\text { GMM }\end{array}$} \\
\hline & $\begin{array}{c}\text { 0,5 salário } \\
\text { mínimo }\end{array}$ & $\begin{array}{l}1 \text { salário } \\
\text { mínimo }\end{array}$ & $\begin{array}{c}\text { 0,5 salário } \\
\text { mínimo }\end{array}$ & $\begin{array}{l}1 \text { salário } \\
\text { mínimo }\end{array}$ & $\begin{array}{c}0,5 \text { salário } \\
\text { mínimo }\end{array}$ & $\begin{array}{l}1 \text { salário } \\
\text { mínimo }\end{array}$ \\
\hline \multicolumn{7}{|l|}{ Variável de Política } \\
\hline beneficio Bolsa Família & $\begin{array}{l}-0,054 \\
(0,055)\end{array}$ & $\begin{array}{l}-0,038 \\
(0,051) \\
\end{array}$ & $\begin{array}{c}-0,843^{* *} \\
(0,194)\end{array}$ & $\begin{array}{c}-0,536^{* *} \\
(0,165)\end{array}$ & $\begin{array}{c}-1,486^{* *} \\
(0,450)\end{array}$ & $\begin{array}{c}-1,410^{* *} \\
(0,426)\end{array}$ \\
\hline \multicolumn{7}{|c|}{ Características Individuais e de Comportamento } \\
\hline idade19 & $\begin{array}{c}-0,333^{* *} \\
(0,069)\end{array}$ & $\begin{array}{c}-0,318^{* *} \\
(0,060)\end{array}$ & $\begin{array}{c}-0,311^{* *} \\
(0,072)\end{array}$ & $\begin{array}{c}-0,306^{* *} \\
(0,062)\end{array}$ & $\begin{array}{c}-0,351^{* *} \\
(0,073)\end{array}$ & $\begin{array}{c}-0,333^{* *} \\
(0,064)\end{array}$ \\
\hline idade29 & $\begin{array}{c}-0,208^{* *} \\
(0,062)\end{array}$ & $\begin{array}{c}-0,151^{* *} \\
(0,053)\end{array}$ & $\begin{array}{c}-0,221^{* *} \\
(0,061)\end{array}$ & $\begin{array}{c}-0,160^{* *} \\
(0,052)\end{array}$ & $\begin{array}{c}-0,186^{* *} \\
(0,067)\end{array}$ & $\begin{array}{c}-0,135^{*} \\
(0,056)\end{array}$ \\
\hline idade34 & $\begin{array}{c}-0,526^{* *} \\
(0,087)\end{array}$ & $\begin{array}{c}-0,372^{* *} \\
(0,070)\end{array}$ & $\begin{array}{c}-0,531^{* *} \\
(0,088)\end{array}$ & $\begin{array}{c}-0,372^{* *} \\
(0,070)\end{array}$ & $\begin{array}{c}-0,510^{* *} \\
(0,092)\end{array}$ & $\begin{array}{c}-0,364^{* *} \\
(0,074)\end{array}$ \\
\hline idade39 & $\begin{array}{c}-1,132^{* *} \\
(0,139)\end{array}$ & $\begin{array}{c}-1,066^{* *} \\
(0,119)\end{array}$ & $\begin{array}{c}-1,183^{* *} \\
(0,139)\end{array}$ & $\begin{array}{c}-1,093^{* *} \\
(0,123)\end{array}$ & $\begin{array}{c}-1,166^{* *} \\
(0,143)\end{array}$ & $\begin{array}{c}-1,087^{* *} \\
(0,125)\end{array}$ \\
\hline idade44 & $\begin{array}{c}-2,261^{* *} \\
(0,309)\end{array}$ & $\begin{array}{c}-1,930 \text { ** } \\
(0,215)\end{array}$ & $\begin{array}{c}-2,325^{* *} \\
(0,370)\end{array}$ & $\begin{array}{c}-1,976^{* *} \\
(0,212)\end{array}$ & $\begin{array}{c}-2,279^{* *} \\
(0,315)\end{array}$ & $\begin{array}{c}-1,962^{* *} \\
(0,213)\end{array}$ \\
\hline cor_branca & $\begin{array}{c}0,069 \\
(0,052)\end{array}$ & $\begin{array}{c}0,051 \\
(0,044)\end{array}$ & $\begin{array}{c}0,033 \\
(0,051)\end{array}$ & $\begin{array}{c}0,036 \\
(0,043)\end{array}$ & $\begin{array}{c}0,027 \\
(0,056)\end{array}$ & $\begin{array}{c}0,017 \\
(0,046)\end{array}$ \\
\hline cor_negra & $\begin{array}{c}0,006 \\
(0,087)\end{array}$ & $\begin{array}{l}-0,035 \\
(0,077)\end{array}$ & $\begin{array}{l}-0,003 \\
(0,084)\end{array}$ & $\begin{array}{l}-0,036 \\
(0,073)\end{array}$ & $\begin{array}{l}-0,006 \\
(0,093)\end{array}$ & $\begin{array}{l}-0,044 \\
(0,080)\end{array}$ \\
\hline cor_outras & $\begin{array}{l}-0,017 \\
(0,105)\end{array}$ & $\begin{array}{l}-0,083 \\
(0,095)\end{array}$ & $\begin{array}{l}-0,098 \\
(0,106)\end{array}$ & $\begin{array}{l}-0,116 \\
(0,097)\end{array}$ & $\begin{array}{l}-0,117 \\
(0,109)\end{array}$ & $\begin{array}{l}-0,165 \\
(0,098)\end{array}$ \\
\hline religião_sem & $\begin{array}{c}0,116 \\
(0,077)\end{array}$ & $\begin{array}{l}0,152 * \\
(0,065)\end{array}$ & $\begin{array}{c}0,092 \\
(0,077)\end{array}$ & $\begin{array}{l}0,142 * \\
(0,064)\end{array}$ & $\begin{array}{c}0,071 \\
(0,087)\end{array}$ & $\begin{array}{c}0,126 \\
(0,070)\end{array}$ \\
\hline religião_evangélica & $\begin{array}{l}-0,018 \\
(0,058)\end{array}$ & $\begin{array}{l}-0,033 \\
(0,048)\end{array}$ & $\begin{array}{l}-0,074 \\
(0,059)\end{array}$ & $\begin{array}{l}-0,057 \\
(0,049)\end{array}$ & $\begin{array}{l}-0,115 \\
(0,067)\end{array}$ & $\begin{array}{l}-0,093 \\
(0,053)\end{array}$ \\
\hline religião_outra & $\begin{array}{l}-0,029 \\
(0,182)\end{array}$ & $\begin{array}{l}-0,151 \\
(0,154)\end{array}$ & $\begin{array}{c}-0,03 \\
(0,187)\end{array}$ & $\begin{array}{l}-0,151 \\
(0,160)\end{array}$ & $\begin{array}{l}-0,087 \\
(0,198)\end{array}$ & $\begin{array}{l}-0,187 \\
(0,166)\end{array}$ \\
\hline \multicolumn{7}{|l|}{ Características Familiares } \\
\hline união_formal & $\begin{array}{l}1,250^{* *} \\
(0,113)\end{array}$ & $\begin{array}{l}1,294^{* *} \\
(0,105)\end{array}$ & $\begin{array}{l}1,268^{* *} \\
(0,113)\end{array}$ & $\begin{array}{l}1,280^{\text {** }} \\
(0,105)\end{array}$ & $\begin{array}{l}1,227^{* *} \\
(0,120)\end{array}$ & $\begin{array}{l}1,235^{* *} \\
(0,108)\end{array}$ \\
\hline união_informal & $\begin{array}{l}1,372^{* *} \\
(0,103)\end{array}$ & $\begin{array}{l}1,405^{* *} \\
(0,100)\end{array}$ & $\begin{array}{l}1,361^{* *} \\
(0,104)\end{array}$ & $\begin{array}{c}1,386^{* *} \\
(0,100)\end{array}$ & $\begin{array}{c}1,274^{* *} \\
(0,113)\end{array}$ & $\begin{array}{l}1,307^{\text {** }} \\
(0,104)\end{array}$ \\
\hline arranjo_casal sem filhos & $\begin{array}{c}-2,209^{* *} \\
(0,366)\end{array}$ & $\begin{array}{c}-2,410^{* *} \\
(0,278)\end{array}$ & $\begin{array}{c}-2,255^{* *} \\
(0,367)\end{array}$ & $\begin{array}{c}-2,430 \text { ** } \\
(0,275)\end{array}$ & $\begin{array}{c}-2,185^{* *} \\
(0,370)\end{array}$ & $\begin{array}{c}-2,359^{* *} \\
(0,271)\end{array}$ \\
\hline arranjo_monoparental pai & $\begin{array}{c}0,309 \\
(0,216)\end{array}$ & $\begin{array}{l}0,200 \\
(0,222)\end{array}$ & $\begin{array}{c}0,161 \\
(0,212)\end{array}$ & $\begin{array}{c}0,125 \\
(0,216)\end{array}$ & $\begin{array}{l}0,127 \\
(0,233)\end{array}$ & $\begin{array}{l}0,057 \\
(0,235)\end{array}$ \\
\hline arranjo_monoparental mãe & $\begin{array}{c}0,426^{* *} \\
(0,102)\end{array}$ & $\begin{array}{c}0,477^{* *} \\
(0,092)\end{array}$ & $\begin{array}{c}0,354^{* *} \\
(0,106)\end{array}$ & $\begin{array}{c}0,446^{* *} \\
(0,094)\end{array}$ & $\begin{array}{l}0,282 * \\
(0,115)\end{array}$ & $\begin{array}{l}0,370^{* *} \\
(0,101)\end{array}$ \\
\hline
\end{tabular}




\begin{tabular}{|c|c|c|c|c|c|c|}
\hline \multirow[t]{2}{*}{ arranjo_outro } & $-0,210$ & $-0,462$ & $-0,261$ & $-0,486$ & $-0,407$ & $-0,614^{*}$ \\
\hline & $(0,287)$ & $(0,278)$ & $(0,290)$ & $(0,268)$ & $(0,303)$ & $(0,276)$ \\
\hline \multirow[t]{2}{*}{ parentesco_chefe } & 0,072 & 0,007 & 0,182 & 0,044 & 0,227 & 0,101 \\
\hline & $(0,164)$ & $(0,135)$ & $(0,165)$ & $(0,136)$ & $(0,184)$ & $(0,145)$ \\
\hline \multirow[t]{2}{*}{ parentesco_filha } & $-0,558^{* *}$ & $-0,686^{* *}$ & $-0,430^{* *}$ & $-0,633^{* *}$ & $-0,336^{* *}$ & $-0,525^{* *}$ \\
\hline & $(0,103)$ & $(0,093)$ & $(0,103)$ & $(0,091)$ & $(0,108)$ & $(0,095)$ \\
\hline \multirow[t]{2}{*}{ parentesco_outro } & $-0,607^{* *}$ & $-0,655^{* *}$ & $-0,579^{* *}$ & $-0,650^{* *}$ & $-0,452^{* *}$ & $-0,524^{* *}$ \\
\hline & $(0,108)$ & $(0,101)$ & $(0,102)$ & $(0,096)$ & $(0,122)$ & $(0,111)$ \\
\hline \multirow[t]{2}{*}{ densidade domiciliar } & $0,167^{* *}$ & $0,193^{* *}$ & $0,176^{* *}$ & $0,198^{* *}$ & $0,177^{* *}$ & $0,205^{* *}$ \\
\hline & $(0,016)$ & $(0,015)$ & $(0,021)$ & $(0,020)$ & $(0,017)$ & $(0,016)$ \\
\hline \multirow[t]{2}{*}{ renda_smpc } & $-0,904^{* *}$ & $-0,848^{* *}$ & $-1,525^{* *}$ & $-1,110^{* *}$ & $-1,710^{* *}$ & $-1,324^{* *}$ \\
\hline & $(0,194)$ & $(0,099)$ & $(0,235)$ & $(0,131)$ & $(0,275)$ & $(0,144)$ \\
\hline \multicolumn{7}{|c|}{ Capital Humano e Conhecimentos Relacionados } \\
\hline \multirow[t]{2}{*}{ educação4 } & 0,119 & 0,030 & 0,102 & 0,018 & 0,054 & $-0,032$ \\
\hline & $(0,221)$ & $(0,216)$ & $(0,224)$ & $(0,217)$ & $(0,240)$ & $(0,233)$ \\
\hline \multirow[t]{2}{*}{ educação8 } & 0,120 & 0,049 & 0,083 & 0,022 & 0,067 & $-0,016$ \\
\hline & $(0,219)$ & $(0,213)$ & $(0,221)$ & $(0,215)$ & $(0,235)$ & $(0,229)$ \\
\hline \multirow[t]{2}{*}{ educação11 } & 0,072 & 0,021 & 0,026 & $-0,013$ & $-0,024$ & $-0,088$ \\
\hline & $(0,223)$ & $(0,216)$ & $(0,225)$ & $(0,218)$ & $(0,238)$ & $(0,231)$ \\
\hline \multirow[t]{2}{*}{ educação12m } & 0,158 & 0,224 & 0,021 & 0,174 & $-0,045$ & 0,073 \\
\hline & $(0,340)$ & $(0,253)$ & $(0,344)$ & $(0,255)$ & $(0,365)$ & $(0,268)$ \\
\hline \multirow[t]{2}{*}{ método contraceptivo } & $-0,027$ & $-0,097$ & $-0,016$ & $-0,079$ & $-0,032$ & $-0,087$ \\
\hline & $(0,142)$ & $(0,129)$ & $(0,142)$ & $(0,127)$ & $(0,152)$ & $(0,134)$ \\
\hline \multirow[t]{2}{*}{ planejamento familiar } & $-0,166^{* *}$ & $-0,161^{* *}$ & $-0,163^{* *}$ & $-0,162 * *$ & $-0,138^{*}$ & $-0,146$ * \\
\hline & $(0,059)$ & $(0,052)$ & $(0,059)$ & $(0,052)$ & $(0,067)$ & $(0,058)$ \\
\hline \multicolumn{7}{|l|}{ Oferta de Serviços } \\
\hline \multirow[t]{2}{*}{ residência urbana } & 0,032 & 0,050 & 0,043 & 0,053 & 0,065 & 0,071 \\
\hline & $(0,051)$ & $(0,045)$ & $(0,048)$ & $(0,044)$ & $(0,056)$ & $(0,049)$ \\
\hline cuidado médico_ & $0,124^{*}$ & $0,104^{*}$ & $0,128 *$ & $0,103^{*}$ & $0,124^{*}$ & $0,095^{*}$ \\
\hline onde procurar & $(0,052)$ & $(0,045)$ & $(0,052)$ & $(0,044)$ & $(0,057)$ & $(0,047)$ \\
\hline cuidado médico_ & 0,009 & 0,038 & $-0,003$ & 0,027 & $-0,018$ & 0,015 \\
\hline considera longe & $(0,051)$ & $(0,045)$ & $(0,051)$ & $(0,044)$ & $(0,057)$ & $(0,048)$ \\
\hline cuidado médico_ & $-0,083$ & $-0,146^{* *}$ & $-0,067$ & $-0,134^{* *}$ & $-0,060$ & $-0,136^{* *}$ \\
\hline medo de não ser atendida & $(0,053)$ & $(0,044)$ & $(0,053)$ & $(0,044)$ & $(0,059)$ & $(0,048)$ \\
\hline \multicolumn{7}{|l|}{ Fatores de Risco } \\
\hline \multirow[t]{2}{*}{ filhos maiores de 2,5anos } & $-0,415^{* *}$ & $-0,506^{* *}$ & $-0,323^{* *}$ & $-0,459^{* *}$ & $-0,279^{* *}$ & $-0,397^{* *}$ \\
\hline & $(0,039)$ & $(0,035)$ & $(0,045)$ & $(0,039)$ & $(0,05)$ & $(0,043)$ \\
\hline \multirow[t]{2}{*}{ imc } & $0,014^{* *}$ & $0,017^{* *}$ & $0,013^{* *}$ & $0,016^{* *}$ & $0,014^{* *}$ & $0,017^{* *}$ \\
\hline & $(0,004)$ & $(0,003)$ & $(0,004)$ & $(0,003)$ & $(0,005)$ & $(0,004)$ \\
\hline \multirow[t]{2}{*}{ fumante } & 0,016 & $-0,0430$ & $-0,004$ & $-0,054$ & $-0,021$ & $-0,066$ \\
\hline & $(0,074)$ & $(0,067)$ & $(0,077)$ & $(0,069)$ & $(0,080)$ & $(0,071)$ \\
\hline
\end{tabular}




\begin{tabular}{|c|c|c|c|c|c|c|}
\hline \multicolumn{7}{|l|}{ Vizinhança } \\
\hline \multirow[t]{2}{*}{ total de vizinhos_crianças } & $0,015^{* *}$ & $0,012^{* *}$ & $0,014^{*}$ & $0,013 *$ & $0,015^{*}$ & $0,013^{*}$ \\
\hline & $(0,005)$ & $(0,004)$ & $(0,006)$ & $(0,005)$ & $(0,006)$ & $(0,005)$ \\
\hline percentual de & $-0,766$ & $-0,767^{*}$ & $-0,912 *$ & $-0,876 *$ & $-0,959 *$ & $-0,947^{*}$ \\
\hline vizinhos_mulheres & $(0,427)$ & $(0,358)$ & $(0,455)$ & $(0,377)$ & $(0,482)$ & $(0,393)$ \\
\hline \multirow[t]{3}{*}{$\Psi$} & - & - & $0,504^{* *}$ & $0,315^{* *}$ & - & - \\
\hline & & & $(0,122)$ & $(0,108)$ & & \\
\hline & $n=3445$ & $n=5355$ & $n=3445$ & $n=5355$ & $n=3445$ & $n=5355$ \\
\hline \multicolumn{7}{|c|}{$\begin{array}{l}\text { Constante omitida. Categorias de referência: idade24, cor_parda, religião_católica, união_sem, arranjo_casal com filhos, } \\
\text { parentesco_cônjuge, educação0. Salário mínimo vigente na data da realização da PNDS 2006: R\$350,00. Desvio padrão entre }\end{array}$} \\
\hline
\end{tabular}

Tabela A-3: Testes de Endogeneidade e Qualidade dos Instrumentos

\begin{tabular}{lcc}
\hline & $\begin{array}{c}0,5 \text { salário } \\
\text { mínimo }\end{array}$ & $\begin{array}{c}1 \text { salário } \\
\text { mínimo }\end{array}$ \\
\hline Teste de endogeneidade dos instrumentos & & \\
$H_{0}:$ Variável de Política é Exógena & & $10,23^{*}$ \\
Hausman $\sim \chi_{(1)}^{2}$ & $10,52^{*}$ & $3,09^{*}$ \\
Wald - inclusão do resíduo $\sim N(0,1)$ & $4,11^{*}$ & $3,05^{*}$ \\
Wald - inclusão da razão inversa de Mills $\sim N(0,1)$ & $4,30^{*}$ & \\
\hline Teste de Qualidade dos Instrumentos & & \\
$H_{0}: E[\varepsilon \mid z]=0$ & 2,945 & 2,480 \\
$J$ de Hansen $\sim \chi_{(2)}^{2}$ & $(p=0,2293)$ & $(p=0,2894)$ \\
& $n=3445$ & $n=53554$ \\
\hline
\end{tabular}

Fonte: Amostra coletada na Pesquisa Nacional de Demografia e Saúde da Criança e da Mulher (PNDS) 2006, (elaboração própria).

Salário mínimo vigente na data da realização da PNDS 2006: R\$350,00.

1 Testes extraídos de Staub (2009). * Significante a 5\%. 